Reshaping the Bottom Line: OnFarm Strategies for a Sustainable Agriculture is a 50-page booklet describing Midwestern management strategies including effective use of nitrogen, building organic matter in soils, controlling weeds and insects, improving pastures, and growing alternative crops. Copies are $\$ 8$ postpaid from the Land Stewardship Project, P.O. Box 412, Lewiston, MN 55952.

Resourceful Farming: A Primer for Family Farmers is a 120-page report on the on-farm research of Nebraska's Small Farm Resources Project. Topics include soil building, alternative crops, biological controls, and more. Each section describes the practices used on the farms and gives further sources for information. Copies are $\$ 7$ from the Center for Rural Affairs, P.O. Box 736, Hartington, NE 68739.

California Small Family Farmers, a 148-page + appendix report conducted by the Jeff Chandler Associates on behalf of the California Energy Commission, points to a positive future for such small farms. "We determined that the number could grow if the farms are managed properly, emphasize marketing, and have access to financing and technological improvements," says Chandler. Copies are $\$ 12$ plus $\$ 2$ handling from Jeff Chandler Associates, 1114 - 21st Street, Sacramento, CA 95814.

Farm Chemicals in Groundwater: Strategies for Nonprofits examines 5 statewide organizations that are successfully dealing with the problem of farm chemical contamination of ground water. The report features the California Institute for Rural Studies and California Action Network, the Center for Rural Affairs, the Iowa Natural Heritage Foundation, the Practical Farmers of Iowa, and the Texas Center for Policy Studies. Copies are $\$ 8$ from Loni Kemp, the Minnesota Project, Southeast Office, Box 4, Preston, MN 55965.

Agroecology: The Scientific Basis of Alternative Agriculture, by Miguel Altieri, discusses the theoretical basis of agricultural ecology, the design of alternative agriculture production systems, ecological management of pests, disease, and weeds, and the process of changing to a more sustainable agriculture. The book is $\$ 21$ from Westview Press, 5500 Central Avenue, Boulder, CO 80301.

USDA Bibliographies on the following topics are available. To request, give the title and Q.B. number, along with a self-addressed label. Send to Reference Branch, Room 111, National Agricultural Library, Beltsville, MD 20705.

Paulownia: Potential Tree-Crop, 1970-87 (Q.B. 88-11). Has 121 citations in many languages.

Potential New Crops: Crambe, 197087 (Q.B. 88-12). Has 166 citations in all languages.

Breeding Crops for Insect Pest Resistance, 1979-87 (Q.B. 88-21). Has 307 citations in English only.

Agriculture: $A$ Look to the Future, 1979-87 (Q.B. 88-22). Has 182 citations in many languages.

Herbicides: Ecological Effects, 198287 (Q.B. 88-24). Has 186 citations in English only.

Alternative Crops, 1970-98 (Q.B. 8825). Has 230 citations in many languages.

Poultry Wastes: Uses and Management, $1979-87$ (Q.B. 88-26). Has 200 citations in English only.

\title{
LETTEAS
}

\section{Favors journal's approach}

I'm writing to thank you for another fine issue of the American Journal of Alternative Agriculture. As with previous issues, the Summer 1987 edition was loaded with useful information. I especially appreciate the Journal's willingness to take on not only important research topics, but issues involving public policy as well. It has become increasingly obvious that wide-spread adoption of sustainable farming methods depends on improving public policies as well as research approaches. In that regard I found both Malcolm $\mathbf{H}$. Fleming's article on removing barriers against low-input farm management and William Lockeretz's commentary on the proper role for on-farm research informative and thought provoking. Both articles offer bold solutions to policy and research problems and deserve to be read and considered by everyone concerned about the course of American agriculture.

The Land Stewardship Project and the Center for Rural Affairs recently co-sponsored a meeting where 30 representatives from non-profit groups and government agencies involved in low-input agriculture in the Midwest met to discuss proposed changes to state and federal policies that would encourage adoption of sustainable farming practices. I mailed a copy of Mr. Fleming's article to all the participants before the meeting. As I had hoped, it did a great job of providing background and raising issues for discussion at the meeting. Thanks again.

Ron Kroese

Executive Director

Land Stewardship Project

512 West Elm Street

Stillwater, $M N 55082$

\section{Farming systems symposium}

I am writing regarding the on-farm research Commentary by William Lockeretz in the Summer, 1987 edition. While I agree with most of what Dr. Lockeretz says, the article conveys the idea that little is known or being done about on-farm research. He recommends the formation of a working group of on-farm researchers with periodic meetings where there will be an opportunity to exchange "on the ground" experience. I recommend that he and others interested in discussions about on-farm research plan to attend the eighth annual International Farming Systems Symposium which will be held at the University of Arkansas in Fayetteville, Arkansas, October 9 to 12 , 1988. This is a gathering of researchers and extensionists from around the United States and much of 